\title{
AUTONOMIA UNIVERSITÁRIA FINANCEIRA: a atual realidade da universidade estadual do Mato Grosso do Sul - UEMS
}

\author{
UNIVERSITY FINANCIAL AUTONOMY: The current reality of the state \\ University of Mato Grosso do Sul - UEMS
}

Marcos Antonio Vieira ${ }^{1}$

Fabrício Antonio Deffacci ${ }^{2}$

\section{Resumo}

Este artigo tem como objetivo descrever os assuntos atinentes à autonomia da Universidade Estadual de Mato Grosso do Sul (UEMS) para se realizar o ensino público em nível superior. Para tanto, faz-se necessário observar os incentivos e os sinais que a sociedade evidencia diante da melhoria da qualidade e o aumento da eficiência como forma de resposta aos anseios administrativos, operacionais e financeiros da instituição. A abordagem utilizada é a Qualitativa, e tem como fonte de análise o acervo bibliográfico, à luz dos teóricos Chauí (2003), Cunha (1980), Durhan (2005), Fávero (2006) e Michelotto (2006). Identificou-se que a política de valorização do privado tem consumido recursos que poderiam ser destinados à ampliação do ensino público superior. No próprio ensino público tem-se buscado subterfúgios para que os alunos custeiem seus cursos, com cobranças autorizadas em cursos de especialização, o que não é diferente com as novas políticas da UEMS. Conclui-se que as instituições de ensino superior, em especial, a UEMS, ao possibilitar cobranças de taxas na universidade passam para a sociedade sua responsabilidade de custear o ensino, com Estado Mínimo em investimentos.

Palavras-chave: Constituição Federal. UEMS. Autonomia financeira.

\footnotetext{
${ }^{1}$ Docente do curso de Direito na UEMS. Mestre do Programa de Pós-Graduação em Educação da UEMS-Paranaíba (2017). Especialização em Direito pela Associação de Ensino e Cultura de Mato Grosso do Sul (2004). E-mail: marcosvieira_adv@hotmail.com

2 Docente da UEMS nos cursos de Ciências Sociais de Amambai e do Programa de PósGraduação em Educação da UEMS de Paranaíba. E-mail: fabricioad@uems.br
} 


\begin{abstract}
This article had as objective to describe the issues related to the autonomy of the State University of Mato Grosso do Sul (UEMS) to conduct public education on higher education, and it is necessary to observe the incentives and signals that society highlights on improving quality and increasing efficiency as a way of responding to the administrative, operational and financial concerns of the institution. The approach used is qualitative, having as a source of analysis the bibliographic collection, in the light of the theoretical Chauí (2003), Cunha (1980), Durhan (2005), Fávero (2006) and Michelotto (2006). It was identified that the private valuation policy has consumed resources that could be earmarked for expansion of the public higher education. In his own public education has sought subterfuge for students to pay for their courses, with charges authorized in specialization courses, which is not different with the new policies of UEMS. It is concluded that the institutions, especially the UEMS, by enabling rates charges at the University passes on its responsibility to fund education for society, with minimum state of investments.
\end{abstract}

Key-words: Federal Constitution. UEMS. Financial autonomy.

\title{
Introdução
}

A autonomia universitária tem sido discutida desde a gênese da criação das instituições voltadas ao ensino superior. Ora mais implícita, ora mais explicitamente, o poder público tem cerceado ou incentivado as universidades, seja por meio do aumento de recursos financeiros a ela destinados e pela concessão de maior independência administrativa para o desenvolvimento das atividades de ensino e pesquisa, seja, por outro lado, com a retirada de recursos; interferência direta em seus rumos; imposição de cursos e currículos e ainda pela restrição de sua liberdade de produção de conhecimento científico, uma vez que a pesquisa implica, necessariamente, investimentos. 
Durham (2005), por sua vez, define enfaticamente essa autonomia como tão somente "[...] a capacidade de reger-se por leis próprias" (DURHAM, 2005, p. 87). Etimologicamente, o termo é - segundo essa autora - confundido com "soberania" e "se aplica integralmente e mais apropriadamente às nações". A antropóloga suscita um amplo esclarecimento acerca da questão em seu artigo: "A autonomia universitária: o princípio constitucional e suas implicações", cuja leitura faz emergir a concepção de que a autonomia não confere uma liberdade absoluta.

A autora Durham (2005, p.11, grifo nosso) ainda salienta que "[...] a autonomia da instituição é sempre relativa e deve ser definida como o reconhecimento de sua capacidade de reger-se por suas próprias normas no cumprimento das finalidades sociais às quais se destina". E menciona ainda que:

[...] a universidade goza de autonomia para executar essas atividades que lhe são próprias, e que não são realizadas para seu exclusivo interesse, mas constituem um serviço que presta à sociedade. Como consequência, o reconhecimento da autonomia não exime as instâncias públicas mais amplas da verificação da prestação efetiva desses serviços. (DURHAM, 2005, p. 12).

A relatividade a que se aplica à temática é devida, também, ao constrangimento de natureza material, cultural e política próprias da sociedade na qual a instituição se insere, aponta a autora. Assim, a leitura do referido artigo aponta que desde a Era Medieval a questão da autonomia está posta como relativa, e isso implica no inevitável entendimento de que as universidades sempre estiveram, em sua trajetória histórica, submetidas aos poderes: ora eclesiásticos, ora civis. Tal fato constitui a pedra fundamental de seu caráter universal. 
Desde há muito se discute a temática proposta neste artigo e, ainda hoje - depois de muitos debates, achaques e controvérsias - faz-se de fato necessária a alusiva investida, pois quanto à autonomia financeira das universidades de foro estadual, quando deliberada, promove benefícios ímpares, como pode atestar, por exemplo, o economista Leonardo Velasco Rondon/Instituto de Economia da Universidade Estadual de Campinas UNICAMP.

O modo como as universidades estaduais estão submetidas aos poderes, bem como as formas como elas são gerenciadas e/ou autogerenciadas podem apresentar diferentes resultados. A gerência restritiva ou conservadora caracteriza se como simples outorga de uma autonomia modulada pela vontade política, está calcada na onipotência dos poderes estatais constituídos e considera as autarquias de ensino como qualquer outra. Quando são gerenciadas de forma libertária, defendem o afastamento da competência legislativa do Estado (autogoverno) e ressalvam apenas a prerrogativa estatal de definição dos padrões básicos de ensino para fins de controle de habilitações profissionais. Já a autonomia modulada reconhece a existência de limites impostos pela própria Constituição, dentre os quais os princípios norteadores da Administração Pública (art. 37, caput).

A autonomia não é uma mera garantia institucional da universidade. É um direito fundamental preexistente que se impõe ao constituinte e ao legislador. Todas essas postulações geram os princípios norteadores, que expandem e/ou limitam a autonomia das universidades.

Outra dimensão da autonomia a ser evidenciada nessa discussão é a da autossuficiência financeira, a qual pode ser obtida por meio da prestação de 
serviços educacionais. Encargos docentes, pesquisa e extensão, manutenção da estrutura físico-organizacional, entre outros, quando administrados de maneira independente, de tal modo que o saber universal fosse legitimado diante da sociedade, proporcionaram às academias universitárias a possibilidade de lutarem por sua autonomia e também de merecê-la.

\section{A UEMS e a questão da autonomia universitária}

Em seu histórico a Universidade Estadual de Mato Grosso do Sul (UEMS), com sede na cidade de Dourados, foi criada pela Constituição Estadual de 1979 e ratificada em 1989, conforme o disposto em seu artigo 48, Ato das Disposições Constitucionais Gerais e Transitórias. Segundo Amaral (2002), trata-se de uma Fundação com autonomia didático-científica, administrativa, financeira, disciplinar e patrimonial, de acordo com a Lei Estadual no. 2.583, de 23 de dezembro de 2002, alterada pela Lei no 3.485 , de 21 de dezembro de 2007 e com o Decreto Estadual no 10.511, de 8 de outubro de 2001. Rege-se por seu Estatuto interno, oficializado por meio do Decreto Estadual n 9.337, de 14 de janeiro de 1999.

De acordo com Amaral (2002), a implantação da UEMS ocorreu após a publicação da Lei Estadual no 1.461, de 20 de dezembro de 1993, e do Parecer do Conselho Estadual de Educação de Mato Grosso do Sul CEE/MS no 08, de 09 de fevereiro de 1994. Mais tarde, por meio do Parecer CEE/MS no 215 e da Deliberação CEE/MS no 4.787, ambos de 20 de agosto de 1997, foi-lhe concedido credenciamento por cinco anos, prorrogado até 2003, pela Deliberação CEE/MS no 6.602, de 20 de junho de 2002. 
A Deliberação CEE/MS no 7.447, de 29 de janeiro de 2004, credenciou a UEMS até dezembro de 2008. A Deliberação do CEE/MS n.․ 8955, de 16 de dezembro de 2008, prorroga o ato de Recredenciamento da UEMS, pelo prazo de três anos, a partir de 01/01/2009 a 31/12/2011, segundo a publicação do Diário Oficial do Estado de Mato Grosso do Sul (2008).

Em 1993, foi instituída uma comissão para implantação da UEMS, com o intuito de elaborar uma proposta de universidade que tivesse compromisso com as necessidades regionais, particularmente com os altos índices de professores em exercício sem a devida habilitação, e, ainda, com o desenvolvimento científico, tecnológico e social do Estado.

Com essa finalidade, a UEMS foi implantada em 14 municípios com Unidades de Ensino, hoje Unidades Universitárias, uma vez que, além do ensino, passaram a desenvolver atividades relacionadas à pesquisa e à extensão, essenciais para a consolidação do "fazer universitário". Além da sede em Dourados, essas unidades foram distribuídas nos seguintes Municípios: Aquidauana, Amambai, Cassilândia, Coxim, Glória de Dourados, Ivinhema, Jardim, Maracaju, Mundo Novo, Naviraí, Nova Andradina, Paranaíba, Ponta Porã e Três Lagoas. As informações foram fornecidas pela Universidade Estadual de Mato Grosso do Sul - UEMS (2016). Bem como informa a referida universidade UEMS (2016) em seus dados e em sua Resolução CEPE/UEMS no 040, de 24 de maio de 1996, tornou extinta a Unidade Universitária de Três Lagoas, a partir do mês de agosto daquele ano, tendo em vista que o único curso ofertado (Direito) passou a ser oferecido também pela Universidade Federal de Mato Grosso do Sul (UFMS) e ambas funcionavam no mesmo local. Em 2001, por meio da Resolução COUNI-UEMS 
no 184, de 10 de outubro de 2001, foi criada a Unidade Universitária de Campo Grande.

A universidade tem como eixo principal a sua missão institucional. Assim, a UEMS priorizou a democratização do acesso à educação superior pública, interiorizou suas unidades para mais próximo das demandas, com o propósito de fortalecer a educação básica pela interferência direta no atendimento às necessidades regionais, principalmente de formação de professores, para buscar a equalização da oferta da educação superior no Estado em oportunidades e qualidade.

Inicialmente, a política institucional da UEMS implicava a rotatividade; ou seja, os cursos criados pela universidade oferecidos em uma determinada unidade universitária eram remanejados para outras unidades, após atender à demanda daquela região. Essa concepção, elaborada para atender à necessidade de ensino no Estado, acabava por comprometer a relação entre o ensino, a pesquisa e a extensão, atividades implícitas ao "fazer universitário".

Com a rotatividade dos cursos os professores também eram obrigados a migrar periodicamente para outras unidades, algumas delas distantes mais de $500 \mathrm{~km}$ das outras e esse fato se constituía em um empecilho para formação e consolidação de grupos de pesquisa. Conforme consta no Plano de Desenvolvimento Institucional da UEMS: Projeto Pedagógico Institucional (2014-2018), após a elaboração do primeiro PDI (2001-20017), foi extinta a rotatividade, com vistas a fixar os professores nas unidades universitárias e melhorar a estrutura das bibliotecas e dos laboratórios com livros, materiais e equipamentos necessários e adequados ao desenvolvimento dos cursos ali existentes. 
Nessa direção, o Plano de Desenvolvimento Institucional preconizou a política institucional da UEMS, que passou a priorizar a fixação do professor em apenas uma unidade universitária; a capacitação docente e técnica; a organização e o fortalecimento de grupos de pesquisa; o incentivo à produção docente qualificada e a criação de programas de pós-graduação stricto sensu. Em seu início, a UEMS possuía doze cursos, com dezoito ofertas às comunidades onde estava localizada. Em 2010 a UEMS ofertou um total de 2.300 vagas com cinquenta e duas novas turmas, incluídas as unidades universitárias e a sede da reitoria.

\section{Perfil Institucional da Universidade Estadual de Mato Grosso do Sul}

De acordo com o preconizado no Estatuto Interno da UEMS (1999), as funções de ensino, a elaboração de pesquisa e de estudos de extensão são funções básicas e essenciais da instituição, serão exercidas de modo integrado, sempre em observância às realidades locais, sem causar danos à liberdade acadêmica e ao ambiente universitário.

Assim, a UEMS busca desenvolver o ensino, a pesquisa e a extensão em consonância com a Lei no. 9394/96, Lei de Diretrizes e Bases da Educação Nacional (BRASIL, 1996) e salvaguarda o papel da universidade como instituição social autônoma e fundamental para o fortalecimento da democracia.

Ainda sobre a Lei no. 9394 (BRASIL, 1996), fomenta-se o acesso à educação superior com garantia, por meio de infraestrutura, materiais e programas de capacitação, melhores condições do trabalho docente e discente, na busca da excelência do ensino, da pesquisa e da extensão, bem como a 
promoção de uma postura crítico-reflexiva e humanística de professores e acadêmicos, com vistas ao exercício consciente da profissão e o estímulo ao desenvolvimento do espírito investigativo, objetivando subsidiar a formação de futuros pesquisadores. Também está incluída nessas metas a inclusão digital, de maneira a formar profissionais que possam utilizar recursos tecnológicos no exercício da profissão e da cidadania.

\section{A UEMS e sua estrutura físico-organizacional}

A UEMS - Universidade Estadual de Mato Grosso do Sul, tornou-se ao longo dos anos um importante mecanismo de desenvolvimento e inclusão social. Rompeu paradigmas, ousou criar e incrementar instrumentos que viabilizaram a consolidação de um novo cenário para a Educação, lançou e efetivou empreendimentos no campo do ensino, da pesquisa e da extensão, com uma coordenação de ações que inegavelmente a configuram hoje como usina geradora da ciência e do saber, um dos polos irradiadores da sustentabilidade do desenvolvimento de Mato Grosso do Sul.

Instituída pela Lei Estadual no 1461, de 20 de Dezembro de 1993, credenciada pela Deliberação CEE/MS no 4787 do Conselho Estadual de Educação, tem como princípios norteadores o conhecimento e o desenvolvimento do homem e do meio num processo de integração e participação permanente; a abertura às inovações no âmbito de sua tríplice função: ensino, pesquisa e extensão; o espírito democrático e fraterno na condução de seus objetivos e a liberdade de pensamento e de expressão para o efetivo exercício da cidadania. A Lei Estadual no. 1461 criou a Universidade Estadual de Mato Grosso do Sul e foi publicada no Diário Oficial na cidade de 
Campo Grande, no ano de 1993. (MATO GROSSO DO SUL, 1993), com o objetivo de desenhar um novo cenário educacional no Estado, o qual enfrentava sérios problemas com relação aos ensinos fundamental e médio, principalmente no quesito qualificação do corpo docente. Era necessário criar uma universidade que fosse até o aluno, em função das distâncias e dificuldades de deslocamento; democratizar o acesso ao ensino superior e fortalecer o ensino básico.

Para cumprir essa proposta, em busca de racionalizar recursos públicos, evitar a duplicação de funções, cargos e demais estruturas administrativas e a fragmentação das ações institucionais, a UEMS adotou três estratégias diferenciadas: rotatividade dos cursos, os quais eram permanentes em sua oferta e temporários em sua localização; criação de unidades universitárias em substituição ao modelo de câmpus e estrutura centrada em coordenações de cursos em vez de departamentos. Esse modelo de instituição descentralizada tornou possível a milhares de alunos o acesso a um curso superior.

O Plano de Desenvolvimento Institucional - PDI, "mapa de navegação" da UEMS, instituiu uma política que, além de ampliar o compromisso inicial da universidade, permite seu fortalecimento e contempla as especificidades de cada região do Estado.

Pode-se dizer que a UEMS assumiu novos desafios e está cada vez mais próxima da comunidade; exerce um papel importante no desenvolvimento e nas perspectivas de futuro de Mato Grosso do Sul e assim escreve uma história de luta pela inclusão social na educação, coerente com seu perfil institucional.

Em Mato Grosso do Sul a UEMS oferece atendimento ao Nível Superior em quinze cidades: Amambai, Aquidauana, Campo Grande, Cassilândia, 
Coxim, Dourados, Glória de Dourados, Ivinhema, Jardim, Maracaju, Mundo Novo, Naviraí, Nova Andradina, Paranaíba e Ponta Porã.

\section{Os Recursos didático-pedagógicos da UEMS}

De acordo com o Estatuto da universidade, a missão da UEMS é "gerar e disseminar o conhecimento", com vistas ao desenvolvimento das potencialidades humanas, dos aspectos político, econômico e social do Estado, e com compromisso democrático de proporcionar acesso à educação superior e fortalecer outros níveis de ensino, de modo a consolidar a democracia. (UEMS, 1999). Dessa forma, pode-se observar que todas as ações estão intrinsecamente ligadas, desde o pensamento lógico para a fundação da universidade, até o anseio pelo atendimento com qualidade, tanto para os profissionais do quadro como para a clientela estudantil.

A UEMS é administrada por Estatuto, Regimento Interno, Normas editadas por seus órgãos colegiados e executivos, por normas constitucionais, complementares e ordinárias, tanto por edição federal como por estadual. A universidade trabalha efetivamente com o Conselho Universitário (COUNI), com o Conselho de Ensino, Pesquisa e Extensão (CEPE) e com a Secretaria dos Órgãos Colegiados (SOC).

A Reitoria é um importante órgão executivo superior e articulador na estrutura organizacional, encabeçado pelo Reitor e Vice-Reitor, juntamente com seus órgãos de assessoramento e apoio. Representa legalmente a Instituição de Ensino Superior e ainda exerce a administração superior, a supervisão, prevê e provê recursos, formula políticas e estratégias de 
desenvolvimento e avalia os resultados das atividades acadêmicas, bem como cumpre as deliberações dos colegiados superiores.

O atual Reitor da UEMS é o Prof. Dr. Fábio Edir dos Santos Costa, que juntamente com seu Vice-Reitor Prof. Dr. Laércio Alves de Carvalho, atuam na Coordenação, Supervisão e Controle de Programas, Projetos e Atividades diversificadas atribuídas e correlatas aos seus gabinetes, com mandato vigente de 2015 a 2019.

Os reitores são apoiados pelos Pró-Reitores de Ensino - Prof. Dr. João Mianutti, Pesquisa e Pós-Graduação - Profa. Dra. Luciana Ferreira da Silva, Extensão - Profa. Dra. Márcia Regina Martins Alvarenga, Administração Prof. Dr. Márcio de Araújo Pereira, Desenvolvimento Humano - Profa. Dra. Adriana Rocha de Carvalho Fruguli Moreira, além de quatro Diretorias, oito Assessorias e o Escritório de Representação em Campo Grande-MS.

Os Dados Institucionais da UEMS disponibilizam, potencializam e evidenciam informações que contribuem com o ingresso de acadêmicos nos cursos de graduação por meio de: Sistema de Seleção Unificada (SISU), Processo Seletivo Interno (PSI/UEMS), Transferência Externa e Portadores de Diploma.

Existem também, formas de beneficiar o acadêmico por meio de Bolsas e Benefícios de Apoio Estudantil, tais como: Processos por meio de Editais; PAE - Programa de Assistência Estudantil; Bolsa Permanência; Auxílio Alimentação; Auxílio Moradia; PVU - Programa Vale Universidade; PVUI Programa Vale Universidade Indígena; PIBEX - Programa Institucional de Bolsas de Extensão; PIBIC - Programa Institucional de Bolsas de Iniciação Científica; PIBIC - AAF - Ações Afirmativas; PIBITI - Programa Institucional 
de Bolsas de Iniciação em Desenvolvimento Tecnológico e Inovação; PIBID Programa Institucional de Bolsas de Iniciação à Docência e BOLSA PETROUEMS - Parceria Universidade Petrobrás e UEMS. (UEMS, 1999).

\section{Os Projetos de pesquisa e extensão da UEMS}

Em atenção ao Sistema Nacional de Avaliação da Educação Superior (SINAES) a Avaliação Institucional tem as seguintes metas: melhoria da qualidade de educação superior; orientação da expansão de sua oferta; aumento da eficácia institucional; efetividade acadêmica e social; valorização de sua missão pública, da promoção dos valores democráticos, do respeito à diferença e à diversidade e à afirmação da autonomia e da identidade institucional.

No tocante às modalidades de avaliação, a UEMS dispõe da Autoavaliação ou avaliação interna e da Avaliação Externa. A primeira é coordenada pela Comissão Própria de Avaliação-CPA e com orientações da CONAES, que visa à identificação das fragilidades e potencialidades da instituição. A avaliação externa é realizada por comissões designadas pelo INEP, e na UEMS essa é uma atribuição do Conselho Estadual de Educação e Secretaria Estadual de Educação de Mato Grosso do Sul. Portanto, essas duas modalidades de avaliação vêm integrar e assegurar o alcance dos objetivos preestabelecidos.

A Pró-Reitoria de Pesquisa e Pós-Graduação é responsável pelo planejamento, coordenação, execução, controle, supervisão e avaliação das atividades de pesquisa e pós-graduação da Universidade Estadual de Mato Grosso do Sul, exerce suas competências por meio dos órgãos de Divisão de Pesquisa (iniciação científica e pesquisa), bem como, a divisão de Pós- 
Graduação (pós-graduação Stricto Sensu; pós-graduação Lato Sensu e Capacitação).

A Pró-Reitoria de Extensão, Cultura e Assuntos Comunitários, como já mencionado, é o Órgão Responsável pelo planejamento, coordenação, execução, controle, supervisão e avaliação das atividades de extensão, cultura e assuntos comunitários da instituição.

\section{Princípios norteadores da autonomia universitária}

Embora a autonomia seja um direito inerente às instituições universitárias, ele está previsto ainda no artigo 207 da Constituição da República Federativa do Brasil; portanto, sua conquista deve ser analisada no contexto do próprio texto constitucional, que ora obriga explícita, ora implicitamente, sua inserção no contexto social em que se encontram situadas as Instituições de Ensino Superior.

A autonomia está cercada, desse modo, pela obrigatoriedade de delinear seu conteúdo e pelo grau de envolvimento que deva ter com a sociedade, ou seja, em outras palavras, essa é a responsabilidade social das universidades. A operacionalização da autonomia se processa em concordância com condicionantes, tais como: ferramentas impostas pelo princípio da legalidade (forma dos atos, licitação, concurso, etc.); cultura burocrática; centralização demasiada; fiscalização prévia, quando o correto seria o controle posterior.

Foi retirada a autonomia financeira da UEMS, embora essa modalidade, nas universidades, seja respaldada pela Constituição Federal de 1988 (Art. 207), conforme citado anteriormente, e - no caso da UEMS - também pelo acordo previsto em seu novo Plano de Desenvolvimento Interno - PDI, o qual 
garante que ela dispõe de autonomia didático-científica, administrativa, de gestão financeira, patrimonial e disciplinar. A autonomia financeira e patrimonial, por sua vez, foi conferida, primeiramente, por meio do Decreto $\mathrm{n}^{\mathrm{o}}$ 10.511, de 8 de outubro de 2001, que regulamentou o repasse de verbas em três parcelas mensais.

A partir deste ponto, serão citadas em formato textual dissertativo, as considerações impetradas na Lei Orgânica da Autonomia Universitária, e ainda, ponderações atinentes extraídas de Dissertação de Mestrado de Amaral (2002).

O atual governo federal, seguindo os passos dos governos anteriores, já mostrou sua proposta sobre autonomia universitária por meio do Projeto de Lei Orgânica da Autonomia Universitária nº 118/2003, o qual, em seu art. $6^{\text {o }}$ estabelece que "A universidade goza de autonomia didático-científica, administrativa e de gestão financeira e patrimonial e obedece ao princípio da indissociabilidade entre ensino, pesquisa e extensão". (BRASIL, 2003, p. 2).

A reforma universitária institui autonomia didático-científica, administrativa de gestão patrimonial e financeira nas universidades públicas, mas o conceito de autonomia não é unânime entre a comunidade acadêmica e o governo. Para as universidades, ela significa ter autonomia de gestão financeira de recursos, ou seja, aquela estabelecida na Constituição Federal. Já para o governo essa autonomia deve custar o mínimo de investimentos públicos e levar as universidades a buscarem recursos por meio de parceiras com a sociedade.

Outro ponto fundamental da reforma universitária versa sobre a autonomia financeira e patrimonial, porque com ela logo ressurge a polêmica 
sobre a diversificação. Tanto o Estatuto da UEMS, como o PLC 118, tratam dessa temática. $\mathrm{O}$ art. 46 do estatuto assenta que: “A UEMS poderá obter receitas decorrentes de exploração de seus bens ou de prestação de seus serviços, bem como de produtos de operações de crédito". (UEMS, 1999, p. 17).

No projeto de lei o art. 14 determina: “A autonomia de gestão financeira e patrimonial consiste na capacidade de gerir recursos financeiros e patrimoniais, postos à sua disposição pelo Estado ou recebidos em doação, bem como gerados pela própria universidade". (BRASIL, 2003, p. 4).

O estatuto da UEMS (1999), em seu art. 46, favorece a mercantilização do ensino quando possibilita a já mencionada "prestação de serviços", então entende-se que o princípio da mercantilização do ensino superior também tem sido lentamente materializado no contexto do estado de Mato Grosso do Sul. O Plano Nacional de Educação (2001) convalidou o processo de mercantilização do ensino superior ao sustentar “[...] a ampliação da margem de liberdade das instituições não universitárias".

O mencionado texto legal destacou que algumas instituições não são "vocacionadas" para desenvolverem pesquisa, como por exemplo, os centros universitários que são importantes para a educação superior, principalmente se possuírem ensino de qualidade e eventualmente praticarem a extensão; assim resguardou apenas às universidades a atividade de ensino, pesquisa e extensão. Porém, nem mesmo as universidades têm cumprido esse papel determinado pela Constituição Federal, como é o caso da UEMS e de outras universidades no país que não atendem a esses preceitos constitucionais.

Essa maneira de agir visa a responder às orientações do Banco Mundial para os países em desenvolvimento, ou seja, “[...] a ideia de que a pesquisa é 
coisa para países ricos, que já teriam os recursos materiais e humanos para desenvolvê-la. Aos países pobres cumpriria a tarefa de ampliar mais qualificadamente a massa de consumidores". (DIAS SOBRINHO, 1999, p. 63).

Essas propostas se harmonizam com a política de redução de responsabilidade do Estado com a educação superior, levam as universidades a ingressarem no mercado para vender seus serviços e acabam por provocar concorrência entre instituições, “[...] impondo o pragmatismo como a nova filosofia educacional da instituição universitária". (MANCEBO; SILVA JÚNIOR, 2004, p. 8).

Além dessa crítica, as propostas apresentadas pelo governo podem ser alvo de outras críticas e uma delas é ter-se furtado ao debate democrático com a sociedade civil sobre a reforma universitária. Outro ponto de censura pode ser feito ao art. 13 do referido projeto de lei, que faculta às universidades a admissão, a exoneração e o estabelecimento de planos de carreira e deixa evidente que a carreira única é um empecilho à autonomia universitária.

A UEMS tem uma proposta diferente da apresentada pelo governo, pois a Lei 2.230/2001, a qual estabelece o Plano de Cargos e Salários (PCS), determina que os servidores sejam contratados mediante concurso público de provas e título (art.27). E o servidor aprovado no concurso, após ser nomeado e empossado, será submetido a estágio probatório, de acordo com a legislação em vigor (art. 31), conforme previsto na Lei nº 2.230 (MATO GROSSO DO SUL, 2001) sobre o Plano de Cargos e Carreiras da Fundação Universidade Estadual de Mato Grosso do Sul.

O já mencionado Grupo Interministerial no documento de Bases para o Enfrentamento da Crise Emergencial das Universidades Federais argumenta 
que a autonomia deve ser exercitada juntamente com a sociedade por meio de seus órgãos colegiados. Para isso, o PLC 118 prevê a criação de um Conselho Superior, composto por representantes das universidades públicas e particulares e por representantes do executivo, dos docentes e dos alunos.

A esse Conselho caberá sugerir ações administrativas a serem implementadas pelas instituições de ensino superior e propor modelos para distribuição orçamentária, com o objetivo de fortalecer o sistema das IES, promover integração e coordenar as políticas orçamentárias; estimular ações de cooperação entre as IES; estabelecer e executar a avaliação das universidades, mediante fixação de critérios uniformes (art.17), de acordo com o estipulado na Lei $\mathrm{n}^{\mathrm{o}} 2.230$ (2001) sobre o plano de cargos e carreiras da Fundação Universidade Estadual de Mato Grosso do Sul.

Na UEMS, a administração é exercida por órgãos colegiados superiores como o Conselho Universitário (COUNI) - instância superior, de caráter normativo e deliberativo - e o Conselho de Ensino, Pesquisa e Extensão (CEPE).

Conforme o Estatuto da UEMS, compete ao Conselho Universitário: I exercer a jurisdição superior da UEMS; II - traçar a política universitária e aprovar diretrizes gerais; III- aprovar, em primeira instância, o Estatuto [...]; IV - aprovar o Regimento Geral, ouvido o Conselho de Ensino, Pesquisa e Extensão em matérias acadêmicas; VIII - aprovar o plano de carreira, cargos e salários do pessoal técnico-administrativo, dando-lhe o encaminhamento adequado; IX - deliberar sobre acriação, extinção e modificação de funções de confiança; XVIII - deliberar sobre a alienação de bens móveis; XIX - deliberar sobre a incorporação de entidades e de instituições à Universidade; XX - 
aprovar a proposta orçamentária da UEMS a ser encaminhada ao Governo do Estado. (UEMS, 1999, art. nº 12 e nº. 13).

Assim, vislumbra-se que a referida autonomia da UEMS, bem como das demais universidades, é tutelada pelas leis, pois ela nunca foi plena nas IES de nosso país, embora esteja proclamada na Constituição Federal e em demais normas complementares.

Embora as entidades de classe, associações, sindicatos, comunidade universitária e sociedade estejam lutando de forma mais consciente pela construção da efetiva autonomia universitária, se durante os debates da reforma universitária o Projeto de Lei no 118/2003 for promulgado, mais uma vez a autonomia tão necessária e desejada ficará adiada.

\section{Considerações Finais}

Como se pode perceber pelo texto, a UEMS está apta a desenvolver sua autonomia, tanto no sentido estrito da palavra e suas dicotômicas implicações (a autonomia do saber/ciência e a autonomia financeira da universidade), quanto à previsão constitucional da autonomia universitária, esculpida em seu artigo 207 da Constituição Federal de 1988. As universidades desempenham funções importantes no meio social em que estão inseridas, qual seja, a produção de conhecimento e desenvolvimento científico, e no caso específico, a UEMS não poderia ser diferente em sua missão. Ressalte-se ainda que a grande maioria de seus alunos é do próprio estado, bem como uma quantidade considerável é formada por egressos de escolas públicas locais; portanto, esses podem viver e trabalhar em sua cidade de origem e colaborar de forma significativa para os desenvolvimentos econômico, cultural e social do Estado. 
Importante lembrar que a autonomia financeira foi sensivelmente atingida, quando da revogação de parágrafos da Lei de Autonomia Universitária da UEMS n. 2.583, de 23 de dezembro de 2002, pela Assembléia Legislativa do Estado. Dessa forma, a universidade perde a garantia do duodécimo de 3\% da arrecadação tributária estadual, pago em doze parcelas repasse que não poderia ser inferior ao valor destinado à UEMS no ano anterior.

Segundo o sindicato da UEMS (ADUEMS), desde que o acordo foi pactuado no ano de 2002, o governo Estadual sempre teve dificuldade em atingir a porcentagem prevista em lei. Por consequência, a perda da garantia do referido repasse prejudica o desenvolvimento das várias atividades educacionais em todas as unidades universitárias. Apenas para ilustrar a questão dos repasses, importa lembrar que as três maiores universidades de São Paulo (USP, UNESP E UNICAMP) recebem o percentual de 9,3 da alta arrecadação de ICMS do Estado, o que justifica em parte o seu poderio educacional e sua autonomia financeira.

Mas afirmar hoje, que uma universidade está apta a exercer sua autonomia, não implica dizer que a mesma venha desenvolver na prática essa prerrogativa, pois conforme já se apontou neste artigo, está tutelada e normatizada pela legislação, no contexto do nosso ordenamento jurídico. Dessa forma, não há que se falar na existência da autonomia plena das universidades, mesmo que preconizada na nossa Carta Magna de 1988.

Nos parâmetros constitucionais, a autonomia universitária está definida como a chamada norma autoaplicável, ou norma de eficácia plena de aplicabilidade imediata. Porém, neste caso, inexiste condicionamento de uma 
norma ou outra, já que o texto feito pelo constituinte originário não vincula tal obrigatoriedade para que seja aplicada a tão propalada autonomia universitária, a qual poderá, dessa forma, ser regularizada pela própria norma constitucional e figurar como completa e acabada na essência de sua eficácia, tal como preconiza o princípio da soberania da Carta Magna, acima de qualquer previsão legisferante.

A autonomia universitária deve se pautar no alcance de sua amplitude e limitações constitucionais, observada hierarquicamente a previsão legal inferior, ou seja, se não houver nenhuma proibição, vedação ou até mesmo limitação constitucional, deverá prevalecer o princípio autonômico.

Importante destacar ainda, com respeito à chamada autonomia-fim, por assim dizer as autonomias didática e científica, as universidades devem observar o que dispõem os princípios do mencionado artigo 207 da Constituição Federal de 1988, quando descreve a indissociabilidade entre ensino, pesquisa e extensão, em consonância com o disposto no artigo 206, também da nossa Carta Magna de 1988, especificamente quanto ao pluralismo de ideias e de concepções pedagógicas; gratuidade do ensino público nos estabelecimentos oficiais; gestão democrática do ensino público na forma da lei e a garantia do padrão de qualidade.

Assim, evidencia-se que a autonomia não é uma mera garantia institucional, mas um direito fundamental imposto ao constituinte e ao legislador. Todas essas postulações conduzirão os princípios norteadores, os quais expandem e/ou limitam a autossuficiência das universidades, cujos princípios estão, portanto, diretamente relacionados ao conhecimento 
produzido, às ações de ensino, ao currículo, enfim, a todas as atividades acadêmicas.

\section{Referências}

ALMEIDA, M. H. T. Dilemas da institucionalização das Ciências Sociais no Rio de Janeiro. In: MICELLI, S. (Org.). História das ciências sociais no Brasil. São Paulo, SP: Vértice, Ed. dos Tribunais: IDESP, 1989. p. 188-226.

AMARAL, M. O. A universidade estadual de Mato Grosso do Sul: a criação, a implantação e a aventura do início da caminhada: 1979-1998. 2002. 156 f. Dissertação (Mestrado em Educação) - Universidade Federal de São Carlos, São Carlos, 2002.

BRASIL. Câmara dos Deputados. Projeto de Lei Complementar nº 118 de 13 de dezembro de 2003. Institui a Lei Orgânica da Autonomia Universitária e dá outrasprovidências. Brasília, DF: Senado Federal, 2003. (Mimeo).

. Lei no 10.172, de 9 de janeiro de 2001. Aprova o Plano Nacional de Educação e dá outras providências. Diário Oficial da União, Brasília, 2001. BRASIL. Lei no . 9394/1996, de 20 de dezembro de 1996. Dispõe sobre as diretrizes e bases da educação nacional. Brasília, DF: Senado Federal, 1996.

CHAUI, Marilena. Sociedade, Universidade e Estado: autonomia, dependência e compromisso social. In: SEMINÁRIO UNIVERSIDADE “Por que e como reformar". MEC Brasília, ago. 2003. Disponível em: <http://www.mec.gov.br>. Acesso em: 19 out. 2016.

Constituição da República Federativa do Brasil. 33 ed. São Paulo:

Saraiva, 2004.

CUNHA, L. A. A universidade tempor: o ensino superior da colônia à era Vargas. Rio de Janeiro, RJ: Civilização Brasileira, 1980. 
DELIGDISCH, M. E. A Autonomia universitária didático-científica e o indispensável atendimento aos anseios sociais. In: IV COLÓQUIO INTERNACIONAL SOBRE GESTÃO UNIVERSITÁRIA NA AMÉRICA DO SUL. Florianópolis, SC, 2004.

DIAS SOBRINHO, J. Avaliação e privatização do ensino superior. In: TRINDADE, Hélgio (Org.). Universidade em ruinas na República dos professores. Rio de Janeiro, RJ: Vozes/CIPEDES, 1999. p. 61-72.

DURHAM, E. R. A autonomia universitária: extensão e limites. São Paulo, SP: Núcleo de Pesquisas sobre Ensino Superior da Universidade de São Paulo/USP, 2005.

FÁVERO, M. de L. de A. A universidade no Brasil: das origens à reforma universitária de 1968. Educar, Curitiba, n. 28, p. 17-36, 2006.

MANCEBO, D.; SILVA JUNIOR, J. dos R. A reforma universitária no contexto de um governo popular democrático: primeiras aproximações. In: ANPED, 2004.

Disponível em: <http://www.anped.org.br/reforma universitária1.pdf $>$. Acesso em: 19 mar. 2016.

MATO GROSSO DO SUL (Estado). Deliberação CEE/MS no 7.447, de 29 de janeiro de 2004. Credencia o funcionamento da Universidade Estadual de Mato Grosso do Sul UEMS até dezembro de 2008. Diário Oficial, Campo Grande, 2008.

. Lei n. 2.583, de 23 de dezembro de 2002. Dispõe sobre a autonomia da Universidade Estadual de Mato Grosso do Sul e dá outras providências. Diário Oficial, Campo Grande, 2002.

. Lei no 2.230, de 2 de maio de 2001. Dispõe sobre o Plano de Cargos e carreiras da Fundação Universidade Estadual de Mato Grosso do Sul. Diário Oficial, Campo Grande, 2001.

. Lei n. 1.461, de 20 de dezembro de 1993. Autoriza Poder Executivo a criar a Universidade Estadual de Mato Grosso do Sul. Diário Oficial, Campo Grande, 1993. 
MICHELOTTO, M. R. UFRP: uma universidade para a classe média. In: MOROSINI, M. C. (Org.). A Universidade no Brasil: concepções e modelos. Brasília, DF: IMEP, 2006. p. 73-84.

UNIVERSIDADE ESTADUAL DE MATO GROSSO DO SUL - UEMS. Dados $e$ números. 2016. Disponível em: $<$ http://www.uems.br/imprensa/dados $>$. Acesso em: 14 out. 2016.

Plano de Desenvolvimento Institucional: projeto pedagógico institucional 2014 - 2018. 2014. Disponível em:

$<$ http://www.uems.br/assets/uploads/orgaos_colegiados/4_2014-08-25_13-3156.pdf >. Acesso em: 14 out. 2015.

. Estatuto da Universidade Estadual de Mato Grosso do Sul. Dourados, 15 de Janeiro de 1999. Disponível em:

$<$ http://www.uems.br/assets/uploads/prodhs/legislacoes/4_2014-08-28_11-0237.pdf>. Acesso em: 14 out. 2015.

Recebido: 21 de dezembro de 2016

Aceito: 09 de janeiro de 2017

Publicado: 10 de maio de 2017 